\title{
PENGARUH EDUKASI TERSTRUKTUR DENGAN MEDIA BOOKLET TERHADAP TINGKAT PENGETAHUAN PASIEN DIABETES MELITUS TIPE 2
}

\section{[THE EFFECT OF STRUCTURED EDUCATION WITH BOOKLET MEDIA ON LEVELS OF PATIENT KNOWLEDGE TYPE 2 DIABETES MELLITUS]}

\author{
Mareyke Y.L Sepang , Vina Putri Patandung , Ignatia Yohana Rembet \\ Akademi Keperawatan Gunung Maria Tomohon, Indonesia \\ Email: sepangmareyke275@gmail.com
}

\section{ABSTRAK}

\begin{abstract}
Latar Belakang: Hipoglikemia dan hiperglikemia adalah komplikasi yang menakutkan, berbahaya, dan berpotensi mengancam kehidupan pasien dengan diabetes. Perawat dapat bertindak secara proaktif dan mengubah cara perawatan yang diberikan. Oleh karena itu perlu untuk mengembangkan cara yang aman dan efektif untuk mengelola diabetes dan hiperglikemia secara proaktif baik di rumah sakit maupun di rumah. Salah satu tindakan keperawatan yang sangat penting untuk dilakukan yaitu pemberian edukasi kesehatan secara terstruktur kepada pasien dan keluarga. Tujuan untuk mengetahui pengaruh edukasi terstruktur dengan media booklet terhadap tingkat pengetahuan pasien DMT2 yang dirawat di RSU Gunung Maria. Metode Penelitian ini merupakan penelitian kuantitatif dengan rancangan kuasi eksperimen yang bertujuan mengungkapkan pengaruh antara variabel independen terhadap variabel dependen. Rancangan penelitian dengan pre test dan post test pada semua responden untuk mengetahui pengaruh edukasi terstruktur dengan media booklet terhadap tingkat pengetahuan pasien DMT2 yang dirawat di RSU Gunung Maria. Sampel penelitian ini adalah pasien DMT2 yang dirawat di RSU Gunung Maria, bersedia menjadi responden dengan menandatangani surat persetujuan, mampu membaca, dan mampu berkomunikasi. Sampel yang digunakan berjumlah 44 responden. Hasil Penelitian menunjukkan bahwa terdapat peningkatan tingkat pengetahuan yang signifikan sebelum dan sesudah intervensi, dengan nilai $p<0,05$. Kesimpulan pemberian edukasi terstruktur dengan menggunakan media booklet memiliki pengaruh yang signifikan terhadap tingkat pengetahuan pasien tentang DMT2.
\end{abstract}

Kata kunci : Diabetes Melitus Tipe ; Edukasi Terstruktu; Booklet 


\section{ABSTRACT}

Background: Hypoglycemia and hyperglycemia are complications that are frightening, dangerous, and potentially life threatening to patients with diabetes. Nurses can act proactively and change the way care is given. It is therefore necessary to develop safe and effective ways to proactively manage diabetes and hyperglycemia both in the hospital and at home. One of the nursing actions that is very important to do is providing structured health education to patients and families. Aim: to determine the effect of structured education with booklet media on the level of knowledge of T2DM patients being treated at Gunung Maria General Hospital. Method: This research method is a quantitative study with a quasi-experimental design that aims to reveal the effect of the independent variable on the dependent variable. The research design used pre-test and post-test for all respondents to determine the effect of structured education using booklet media on the level of knowledge of T2DM patients treated at Gunung Maria General Hospital. The sample of this study was T2DM patients who were treated at Gunung Maria General Hospital, willing to become respondents by signing a letter of agreement, able to read, and able to communicate. The sample used was 44 respondents. Results:The results showed that there was a significant increase in the level of knowledge before and after the intervention, with a $p$ value $<0.05$. Conclusion: The conclusion is that structured education using booklet media has a significant effect on the level of patient knowledge about T2DM.

Keywords : Type 2 Diabetes Mellitus; Structured Education; Booklet

\section{PENDAHULUAN}

Penyakit Diabetes merupakan salah satu keadaan darurat kesehatan global terbesar di abad ke-21. Pada tahun 2015 terdapat 415 juta orang dewasa yang menderita diabetes di seluruh dunia, dan diperkirakan terus meningkat hingga pada tahun 2040 mencapai 642 juta jiwa. Indonesia sendiri menempati posisi ke-7 di dunia dengan penderita diabetes dewasa terbanyak yaitu sebesar 10 juta jiwa. Pada tahun 2015, mortalitas penyakit diabetes pada orang dewasa terbilang tinggi yaitu mencapai 5 juta jiwa (International Diabetes Federation, 2015).

Diabetes tipe 2 (DMT2) adalah diabetes yang paling umum dan sering terjadi pada orang dewasa serta telah meningkat seiring dengan perubahan 
budaya dan masyarakat. Di Indonesia khususnya di Sulawesi Utara, prevalensi penyakit DMT2 sebesar 3,6\% dan merupakan propinsi kedua dengan prevalensi tertinggi penderita diabetes. Pada DMT2, tubuh mampu memproduksi insulin namun menjadi resisten sehingga insulin tidak efektif. (Balitbang Kemenkes RI, 2013; International Diabetes Federation, 2015; World Health Organization, 2016).

American Diabetes Association (2017) menyoroti pentingnya perawatan yang berpusat pada pasien dan membuat perawatan yang berkualitas tinggi sebagai prioritas. Perubahan yang meningkatkan kualitas perawatan diabetes diantaranya yaitu mencakup perawatan pada pedoman berbasis bukti; memperluas peran tim untuk menerapkan strategi pengelolaan penyakit yang lebih intensif; memberdayakan dan mendidik pasien; pemantauan glukosa darah, dan obat-obatan yang diperlukan.

Pasien DMT2 dengan hiperglikemia sering mendapatkan perawatan di rumah sakit untuk manajemen kadar glukosa darah agar tidak terjadi komplikasi lebih lanjut ataupun kematian. Hipoglikemia dan hiperglikemia adalah komplikasi yang menakutkan, berbahaya, dan berpotensi mengancam kehidupan pasien dengan diabetes. Jika praktik saat ini menunjukkan peningkatan hasil yang buruk, seperti hipoglikemia atau hiperglikemia, perawat dapat bertindak secara proaktif dan mengubah cara perawatan yang diberikan. Oleh karena itu perlu untuk mengembangkan cara yang aman dan efektif untuk mengelola diabetes dan hiperglikemia secara proaktif baik di rumah sakit maupun di rumah. Salah satu tindakan keperawatan yang sangat penting untuk dilakukan yaitu pemberian edukasi kesehatan secara terstruktur kepada pasien dan keluarga. 
Pemberian edukasi secara terstruktur kepada pasien dan keluarga sangat penting untuk keberhasilan manajemen hiperglikemia dan diabetes yang aman di rumah sakit (Houck, Tirumalasetty and Meadows, 2013). Keterlibatan dari pasien dan keluarga dalam perawatan diabetes akan bermanfaat dalam menurunkan tingkat hiperglikemia dan hipoglikemia yang tidak terkontrol dan bermanfaat juga saat pasien beralih ke perawatan di rumah (Cobaugh et al., 2013). Oleh karena itu, edukasi pada pasien dengan DMT2 untuk hasil klinis yang lebih baik sangat diperlukan (Houck, Tirumalasetty and Meadows, 2013). Edukasi kesehatan yang akan diberikan juga bergantung pada media yang akan digunakan. Media yang digunakan dapat bermacam-macam tergantung dari kebutuhan. Salah satu media edukasi yang dapat digunakan adalah booklet. Penelitian dari Prabawati, Isworo, \& Iskandar (2017) menemukan bahwa pemberian edukasi kesehatan dengan menggunakan booklet meningkatkan motivasi pasien untuk latihan fisik pada pasien diabetes. Begitu juga dengan penelitian dari Puspitasari, Andrajati, \& Bahtiar (2013) menemukan bahwa edukasi kesehatan menggunakan booklet pengobatan efektif membantu meningkatkan kepatuhan pasien.

METODE

PENELITIAN
Penelitian ini merupakan penelitian kuantitatif dengan rancangan kuasi eksperimen yang bertujuan mengungkapkan pengaruh antara variabel independen terhadap variabel dependen. Rancangan penelitian dengan pre test dan post test pada semua responden untuk mengetahui pengaruh edukasi terstruktur dengan media booklet terhadap tingkat pengetahuan pasien DMT2 yang dirawat di RSU Gunung Maria. Sampel penelitian ini adalah pasien DMT2 yang dirawat di RSU Gunung Maria, bersedia menjadi responden dengan menandatangani surat persetujuan, mampu membaca, dan mampu 
berkomunikasi. Sampel yang digunakan berjumlah 44 responden.

HASIL DAN

PEMBAHASAN

Analisis univariat digunakan untuk melihat distribusi karakteristik

responden berdasarkan usia, jenis kelamin, tingkat pendidikan, pekerjaan, penghasilan, dan lama menderita DMT2.

Tabel 1 Distribusi frekuensi responden berdasarkan, jenis kelamin, umur, tingkat pendidikan, pekerjaan, penghasilan, dan lama menderita DMT2 ( $n=44)$

\begin{tabular}{lcc}
\hline \multicolumn{1}{c}{ Variabel } & $\mathbf{n}$ & $\%$ \\
\hline Jenis kelamin: & 10 & \\
Laki-laki & 34 & 22,7 \\
Perempuan & & 77,3 \\
Umur: & 1 & \\
17-25 tahun (remaja akhir) & 1 & 2,3 \\
26-35 tahun (dewasa awal) & 8 & 2,3 \\
36-45 tahun (dewasa akhir) & 6 & 18,2 \\
46-55 tahun (lansia awal) & 18 & 13,6 \\
56-65 tahun (lansia akhir) & 10 & 40,9 \\
>65 tahun (manula) & & 22,7 \\
Tingkat pendidikan: & 12 & \\
SD & 11 & 27,3 \\
SLTP & 13 & 25 \\
SLTA & 8 & 29,5 \\
Sarjana & & 18,2 \\
Pekerjaan: & 24 & 54,5 \\
IRT & 3 & 6,8 \\
Wiraswasta & 5 & 11,4 \\
Tani & 7 & 15,9 \\
PNS & 5 & 11,4 \\
Tidak bekerja/pensiunan & & \\
Penghasilan: & 37 & 84,1 \\
<2.800.000 & 7 & 15,9 \\
>2.800.000 & & \\
Lama menderita DMT2: & 31 & 70,5 \\
<5 tahun & 7 & 15,9 \\
5-10 tahun & 1 & 2,3 \\
11-15 tahun & 5 & 11,4 \\
>15 tahun & & 741 \\
\hline
\end{tabular}


Total responden 44 orang. Responden didominasi perempuan (34 orang, 77,3\%). Umur reponden paling banyak dalam rentang 56-65 tahun (18 orang, 40,9\%). Rata-rata tingkat pendidikan responden adalah SLTA (13 orang, $29,5 \%$ ), dengan pekerjaan yang paling banyak adalah IRT (24 orang, 54,5\%). Penghasilan per bulan responden paling banyak kurang dari 2.800 .000 atau kurang dari UMR (37 orang, 84,1\%). Lama menderita DMT2 paling banyak kurang dari 5 tahun (31 orang, 70,5\%).

Analisis bivariat digunakan untuk melihat perbedaan tingkat pengetahuan sebelum dan sesudah intervensi pemberian edukasi terstruktur menggunakan media booklet dilihat dengan menggunakan uji beda berpasangan non parametrik. Apabila data berdistribusi normal digunakan uji $\mathrm{T}$ berpasangan sedangkan apabila data tidak berdistribusi normal digunakan uji Wilcoxon. Dalam penelitian ini karena data berdistribusi tidak normal maka digunakan uji Wilcoxon.

Tabel 2 Perbedaan tingkat pengetahuan responden sebelum dan sesudah pemberian edukasi terstruktur

\begin{tabular}{lcc}
\hline Variabel & Mean Rank & Nilai $p$ \\
\hline Tingkat pengetahuan sebelum intervensi & 0,00 & 0,000 \\
Tingkat pengetahuan sesudah intervensi & 22,50 & \\
\hline
\end{tabular}

Tabel 2 memperlihatkan perbedaan tingkat pengetahuan responden sebelum dan sesudah intervensi pemberian edukasi terstruktur menggunakan media booklet. Dari hasil analisis, didapatkan nilai $p<0,05$. Ini menunjukkan bahwa terdapat peningkatan tingkat pengetahuan yang signifikan sebelum dan sesudah intervensi.

Hasil penelitian ini memperlihatkan bahwa terdapat perbedaan tingkat pengetahuan responden sebelum dan sesudah intervensi pemberian edukasi 
terstruktur dengan media booklet. Temuan ini sejalan dengan penelitian yang dilakukan oleh Boegner, Fontbonne, Vidal, Mouls, \& Monnier (2008). Penelitian tersebut hendak memperlihatkan manfaat dari program edukasi terstruktur pada pasien DMT2. Hasil penelitian menunjukkan bahwa terdapat peningkatan pengetahuan responden tentang penyakit DMT2 dan responden lebih mengembangkan sikap yang lebih positif terkait diabetes. Beberapa penelitian terkait juga menyatakan bahwa program edukasi yang terstruktur merupakan kunci untuk memfasilitasi perubahan perilaku yang berkelanjutan dan melengkapi seseorang dengan keterampilan yang diperlukan untuk pengelolaan diabetes yang sukses seumur hidup (Jarvis, Skinner, Carey, \& Davies, 2010), meningkatkan kemampuan pasien untuk manajemen diri sendiri dan meningkatkan kepatuhan mereka terhadap pengobatan, sehingga mencapai hasil yang lebih baik (Guo et al, 2014). Edukasi diabetes terstruktur juga efektif dalam meningkatkan pengetahuan tentang penyakit pada orang dewasa dengan DMT2 di Nigeria. Edukasi diabetes terpadu dan intensif merupakan metode yang efektif untuk meningkatkan pengetahuan dan hasil metabolik yang lebih baik. Edukasi pasien dianggap sebagai komponen penting perawatan penyakit kronis dan promosi kesehatan yang efektif (Kolawole et al., 2009). Edukasi terkait diabetes tidak hanya membantu pasien memahami diabetes, perkembangannya, dan kemungkinan komplikasi, namun juga memberikan panduan dan dorongan kepada pasien untuk terlibat secara proaktif dalam mengurangi risiko untuk kesehatan yang optimal (Kent et al., 2013). Edukasi pasien bukan hanya tentang menginformasikan pasien tentang semua masalah kesehatannya, melainkan juga tentang hubungan antara masalah kesehatan dan perilaku pasien (McCleary-Jones, 2011; Sassen, 2017). 
Dari berbagai bukti ilmiah dan uraian di atas diharapkan bagi para petugas kesehatan khususnya para perawat yang ada ruangan rawat inap di rumah sakit dapat memberikan edukasi kesehatan yang terstruktur dengan menggunakan media booklet dengan bahasa yang mudah dipahami oleh pasien dan keluarga agar dapat meningkatkan pengetahuan pasien dan keluarga tentang penyakit DMT2.

Kesimpulan dari hasil penelitian ini adalah terdapat perbedaan tingkat pengetahuan tentang DMT2 yang signifikan sebelum dan sesudah pemberian edukasi terstruktur dengan menggunakan media booklet pada semua responden dalam penelitian ini. Saran: Perawat yang dinas di ruang rawat inap rumah sakit sebaiknya memberikan edukasi kesehatan secara terstruktur kepada pasien DMT2 dengan menggunakan media booklet sehingga pasien dapat memahami tentang penyakit yang diderita terutama untuk mengontrol kadar gula darah pasien.

\section{DAFTAR}

\section{PUSTAKA}

1. Badan Penelitian dan Pengembangan Kesehatan Kementerian Kesehatan RI. (2013). Riset Kesehatan Dasar (RISKESDAS) 2013. Available at: http://www.depkes.go.id/resources/download/general/Hasil Riskesdas 2013 (Accessed: 28 November 2016).

2. Boegner, C. et al. (2008). Evaluation of a structured educational programme for type 2 diabetes patients seen in private practice. Elsevier Masson, 34, pp. 243-249. doi: 10.1016/j.diabet.2008.01.003.

3. Cobaugh, D. J. et al. (2013). Enhancing insulin use safety in hospitals: Practical recommendations from an ASHP Foundation expert consensus panel. American Journal of Health-System Pharmacy, 70(16), pp. 1404-1413. doi: 10.2146/ajhp130169.

4. Guo, X. H. et al. (2014). Efficacy of structured education in patients with type 2 diabetes mellitus receiving insulin treatment. Journal of Diabetes, 6(4), pp. 290-297. doi: 10.1111/1753-0407.12100.

5. Houck, P. M., Tirumalasetty, N. N. and Meadows, R. Y. (2013). Insulin administration and meal delivery coordination for hospitalized patients. Ochsner Journal, 13(3), pp. 327-333. Available at: 
http://www.embase.com/search/results?subaction=viewrecord\&from=expo rt\&id=L369821846\%5Cnhttp://sfxhosted.exlibrisgroup.com/galway?sid=EMB ASE\&issn=15245012\&id=doi:\&atitle=Insulin+administration+and+meal+deliv ery+coordination+for+hospitalized+patients\&stitle.

6. International Diabetes Federation. (2015). IDF Diabetes Atlas Seventh Edition 2015. Brussels. Available at: www.diabetesatlas.org.

7. Jarvis, J. et al. (2010). How can structured self-management patient education improve outcomes in people with type 2 diabetes?. Diabetes, Obesity and Metabolism, 12(1), pp. 12-19. doi: 10.1111/j.14631326.2009.01098.x.

8. Kent, D. et al. (2013). Reducing the Risks of Diabetes Complications Through Diabetes Self-Management Education and Support. Population Health Management, 16(2), pp. 74-81. doi: 10.1089/pop.2012.0020.

9. Kolawole, B. A. et al. (2009). Effectiveness of a Structured Diabetes Education Program on Some Non-Glycemic Endpoints in Nigerians with Type 2 Diabetes Mellitus. International Quarterly of Community Health Education, 29(4), pp. 381-388. doi: 10.2190/IQ.29.4.g.

10.McCleary-Jones, V. (2011). Health literacy and its association with diabetes knowledge, self-efficacy and disease self-management among African Americans with diabetes mellitus. ABNF Journal, 22(2), pp. 25-32. Available at: https://www.ncbi.nlm.nih.gov/pubmed/21675666.

11.Prabawati, S., Isworo, A. and Iskandar, A. (2017). Pengaruh Pendidikan Kesehatan dengan Media Booklet terhadap Motivasi Latihan Fisik Pasien Diabetes Mellitus di Wilayah Kerja Puskesmas Purwokerto Utara. Available at:

https://www.academia.edu/35143434/PENGARUH_PENDIDIKAN_KESEHATA N_DENGAN_MEDIA_BOOKLET_TERHADAP_MOTIVASI_LATIHAN_FISIK_PASIE N_DM.

12.Puspitasari, A. W., R. Andrajati and A. Bahtiar (2013). Analisis Efektivitas Booklet Obat terhadap Tingkat Kepatuhan Pasien Diabetes Melitus tipe-2. Journal of Management and Pharmacy Practice, 2, pp. 1-7.

13.Sassen, B. (2017). Nursing: Health Education and Improving Patient SelfManagement. Switzerland: Springer. doi: 10.1007/978-3-319-51769-8.

14.World Health Organization. (2016). Diabetes. Available at: http://www.who.int/diabetes/global-report/en/ (Accessed: 30 August 2017). 